\title{
Instrumentos de acesso à justiça: releitura a partir da teoria dos jogos
}

\section{Access to justice tools: analysis from game theory}

DOI: 10.46814/lajdv2n4-001

Recebimento dos originais: 10/04/2020

Aceitação para publicação: 10/04/2020

\author{
Jéssica Gonçalves \\ Doutora em Direito pela Universidade Federal de Santa Catarina - UFSC \\ Instituição: Universidade do Vale do Itajaí - UNIVALI \\ R. João Coan, 400 - Universitarios, Biguaçu - SC, 88161-064 \\ E-mail: dra.jessicagoncalves@gmail.com
}

\begin{abstract}
RESUMO
O presente trabalho busca estudar que no contexto Jurídico Brasileiro, os cidadãos, ao submeterem preferencialmente os seus conflitos aos Tribunais, acarretam a criação de um paradigma, consistente na confusão cultural entre o acesso à justiça e a tutela jurisdicional. Ocorre que a formação desse paradigma fomenta a judicialização das demandas, as quais contribuem à manutenção das crises de litigiosidade $\mathrm{e}$ morosidade presentes no Poder Judiciário. A partir disso, reflete-se sobre o tema dos instrumentos Brasileiros na estabilização das controvérsias, dentre eles, a dogmática Processual Civil e a forma alternativa da Mediação, como técnicas para exercer o direito ao Acesso à Justiça que, a partir da releitura pela Teoria dos Jogos, apresentam os litigantes - entendidos como jogadores - enquanto participantes competidores ou cooperadores.
\end{abstract}

Palavras-chave: Acesso à Justiça, Teoria dos Jogos, Processo Civil, Mediação.

\begin{abstract}
his work studies in the Brazilian legal framework, citizens, preferably to submit their disputes to the courts, lead to the creation of a paradigm, consistent cultural confusion between access to justice and judicial protection. It turns out that the formation of this paradigm promotes the legalization of demands, which contribute to the maintenance of litigation crisis and delays present in the judiciary. From this it is reflected on the subject of instruments Brazilian stabilization of controversies, among them the dogmatic Civil Procedure and the alternative form of mediation as techniques to exercise the right to access to justice that, from rereading the Theory Games present litigants - understood as players - while participating competitors or cooperators.
\end{abstract}

Keywords: Access to Justice, Game Theory, Civil Lawsuit, Mediation.

\section{INTRODUÇÃO}

No contexto Jurídico Brasileiro, os cidadãos, ao submeterem preferencialmente os seus conflitos aos Tribunais, acarretam a criação de um paradigma, consistente na confusão cultural entre o acesso à justiça e a tutela jurisdicional. Ocorre que a formação desse paradigma fomenta a judicialização das demandas, as quais contribuem à manutenção das crises de litigiosidade e morosidade presentes no Poder Judiciário. A partir disso, reflete-se sobre o tema dos instrumentos Brasileiros na estabilização das 
controvérsias, dentre eles, a dogmática Processual Civil e a forma alternativa da Mediação, como técnicas para exercer o direito ao Acesso à Justiça que, a partir da releitura pela Teoria dos Jogos, apresentam os litigantes - entendidos como jogadores - enquanto participantes competidores ou cooperadores.

Por essa premissa, o modelo - jogo - de estabilização dos conflitos da tutela jurisdicional pelo Processo civil vincula-se ao jogo de natureza competitiva, focado na necessidade de vencer a qualquer custo, uma vez que os jogadores são impulsionados pela recompensa ao final com o julgamento procedente do pedido. Além disso, o comportamento dos agentes é induzido a não cooperação e ao resultado que soma zero, pelo qual uma parte ganha se a outra perder. Assim, o tratamento dos conflitos pela via jurisdicional é pautado pela disputa acirrada, na qual as controvérsias hão de ser, ao final, atribuídas a uma das partes por um terceiro estranho à relação jurídica, isto é, pelo maniqueísmo de que para que um vença o outro precisa perder, não havendo cooperação, porque isso implicaria na vitória do adversário.

De outro lado, o método da Mediação, enquanto proposta transformadora do conflito, recorda o jogo cooperativo, cuja natureza não adversarial e autocompositiva admite a maximização de ganhos coletivos com resultado diferente de zero, porque ambos participantes colaboram entre si. Sem estar preocupada com a verdade formal dos autos, a Mediação cumpre a função de jogo cooperativo, pois a decisão não será de um, nem do outro, mas de ambos, já que se conciliam os interesses que motivaram as pessoas e não as posições que elas adotam.

Assim, pretendo o artigo, fazer uma releitura dos instrumentos de acesso à justiça segundo o enfoque econômico da Teoria dos Jogos, revelando paradigmas de justiças diversos; sendo a técnica da Mediação, a qual envolve a estratégia da co -participação responsável e se mostra tendente a obtenção do consenso pelo paradigma "ganhador x ganhador" e a lógica do Processo Civil, a qual perfaz a estratégia polarizada da competição e ao termo final pelo "perdedor x ganhador".

\section{O DIREITO AO ACESSO À JUSTIÇA: PARA ALÉM DO PARADIGMA - MODELO - DA TUTELA DO PODER JUDICIÁRIO}

Toda gênese se dá com a disparidade entre o meu e o teu que conjuga o nosso conflito, como elemento intrínseco a existência humana, enquanto passagem histórica e dialética, e, cuja eliminação não pode ocorrer peremptoriamente. Tanto é assim, que o próprio pacto social, de criação do terceiro imparcial e acima das partes, representado pela figura colossal do Leviatã, apenas substitui a vontade das partes - autotutela - e neutraliza provisoriamente os conflitos por meio da função, atividade e do poder de dizer o direito pela jurisdição do Poder judiciário.

E, nessa perspectiva de sinônimo entre a cultura do conflito e a cultura da litigância, sugerindo que a cada novo agravo deva corresponder uma intervenção judicial, é que se criou aquilo que se 
denomina de paradigma; padrão ou modelo aceito, que no Direito significa a identificação cultural de recorrer ao Processo Civil oferecido pela tutela jurisdicional como única via de Acesso à Justiça.

Ocorre que isto é um (pseudo) paradigma, na medida em que o Acesso à Justiça pode ser entendido sob dois fundamentos: sentido estrito de acesso ao Poder Judiciário e sentido amplo de acesso ao Direito. Segundo o referencial teórico dos autores Mauro Capelletti e Bryant Garth (1998, p. 8) o acesso à justiça representa duas singularidades básicas:

[...] A expressão acesso à justiça é reconhecidamente de difícil definição, mas serve para determinar duas finalidades básicas do sistema jurídico - o sistema pelo qual as pessoas podem reivindicar seus direitos e/ou resolver seus litígios sob os auspícios do Estado. Primeiro, o sistema deve ser igualmente acessível a todos; segundo ele deve produzir resultados que sejam individual e socialmente justos.

Em consonância, Horácio Wanderlei Rodrigues (1994, p. 28), sintetiza que a expressão admite duas acepções distintas: a primeira atribui ao significante "justiça" o mesmo sentido e conteúdo de "Poder Judiciário", tornando-as expressões sinônimas e, a segunda, parte da visão axiológica da expressão "justiça" e identifica como acesso a uma ordem determinada de valores e direitos fundamentais para o ser humano, de conteúdo mais amplo, englobando o primeiro termo.

Neste âmbito, uma das formas clássicas de conceituar o Acesso à Justiça é identificá-lo ao acesso ao Poder Judiciário, chegando-se a confundir essas realidades e deixando-se, por regra, os meios alternativos de tratamento de conflitos à margem do conceito de Acesso à Justiça. Como pontua Kazuo Watanabe (2003, p. 53), “temos um meio normal, usual, que é a solução pelo Poder Judiciário, pela autoridade do Estado, e os meios alternativos, ainda em fase de organização. " Dessa forma, ainda se analisa o Acesso à Justiça unicamente como a possibilidade de admissão pelos Tribunais para o exercício da ação judicial, confundindo-o com as garantias processuais fundamentais. Entretanto, o acesso ao Poder Judiciário é apenas via privilegiada para que se encontre a justiça, porém está longe de ser a exclusiva, eis que na sociedade considerada plural, múltiplos também devem ser os mecanismos postos para o tratamento dos conflitos.

Em determinada época podia o Acesso à Justiça ser confundido com o sentido estrito de acesso ao Poder Judiciário, porém, com a expansão da judicialização traduzida na multiplicação no volume dos processos contenciosos, o Estado encontra-se hipertrofiado, não mais atendendo a grande demanda de processos. A via tradicional do Poder Judiciário não se tem manifestada como a melhor forma de satisfazer as pretensões, descortinando-se o ressurgimento da terceira "onda" de justiça pautada no acordo entre as partes (CAPELLETTI; GARTH, 1998, p. 10).

O direito ao Acesso à Justiça não mais pode ser considerado como algo idêntico ao acesso ao Poder Judiciário, devendo o legítimo exercício daquele ser antecedido por uma série de filtros, a fim de 
viabilizar a ordem jurídica justa que englobe outras estruturas para atender às demandas que se lhe apresentem, voltadas para efetivação dos direitos fundamentais. Por esta razão, emprega-se o sentido amplo de direito em estabilizar o conflito, isto é, "a uma determinada ordem de valores e direitos fundamentais do ser humano" (RODRIGUES, 1994, p. 28), ou no mesmo entendimento, "um sistema jurídico moderno e igualitário que pretenda garantir, e não apenas proclamar os direitos de todos. " (CAPPELLETTI; GARTH, 1988, p. 12).

O alargamento do Acesso à Justiça, enquanto direito que não se encerra em uma única forma de tratamento dos conflitos, avulta a repercussão política e social do conceito, cuja fonte é essencial para a consolidação da Democracia e do Estado contemporâneo. Assim, mais do que acesso aos Tribunais, o Acesso à Justiça abrange a solução justa e efetiva por parte do Estado, independe do mecanismo disposto ao cidadão, desde que ocorra a resposta em tempo hábil. O Acesso à Justiça é maximizado pela inclusão de diversos mecanismos que não apenas o Poder Judiciário, devendo ser menos formal para garantir o acesso das pessoas menos instruídas e, ainda, garantir o direito de ação e defesa por diversos mecanismos alternativos que busquem a celeridade e a efetividade.

Sopesado o seu termo, percebe-se que a ideia de Acesso à Justiça significa, hoje, não simplesmente acesso à tutela jurisdicional do Estado, uma vez que se traduz como a generalização de diversos mecanismos para tratamento dos conflitos. Nos termos contemporâneos ambientados no cenário jurídico, as disputas vão além do sistema judiciário, notadamente ao revés de um Poder Judiciário idelogicamente estrategista que retroalimenta a cultura forense.

Dessa forma, embora, também hoje, culturalmente se agregue ao Poder Judiciário, a missão de Acesso à Justiça, insiste-se que a gestão por este poder, basicamente envolta da vitória sobre o adversário, deve "caminhar" ao encontro de formas alternativas no tratamento das demandas, questionando o modelo tradicional e restrito de acesso delimitado pelos resultados, para o enquadramento maximizado de direito humano e fundamental com base na ação social e participativa presente na justiça coexistencial ou conciliatória.

Para essa mudança entre o acesso restrito à tutela judicial e outras formas no tratamento das controvérsias, apresenta-se a clivagem no conteúdo epistemológico da simbiose entre Direito e Economia, notadamente pela teoria de base da Análise Econômica do Direito e seu instrumento microeconômico da Teoria dos Jogos.

\section{ANÁLISE ECONÔMICA DO DIREITO E SEU INSTRUMENTO MICROECONÔMICO DA TEORIA DOS JOGOS}

A Análise Econômica do Direito cresceu como disciplina autônoma, empregando a Teoria Econômica no Direito para compreensão da racionalidade dos sujeitos no sistema legal na medida em que 
aplica suas premissas na elaboração das normas ou no silogismo decisório. Neste âmbito, constitui estudo interdisciplinar entre a Teoria Econômica e o Direito, prescrevendo a definição das "variáveis instrumentais das questões e processos que são fundamentais para o funcionamento das instituições jurídicas que gozam de importância econômica. " (MERCURO, 1991, p. 13).

Assim, a clivagem no conteúdo epistemológico da simbiose entre Direito e a Economia pelo marco teórico da Análise Econômica do Direito demonstra que lócus normativista presente no campo do Direito, tem frequentemente admitido uma abertura cognitiva do discurso economicista na estrutura legal, na medida em que a ciência social aplicada e empírica, liberta o ordenamento jurídico da sua obsessão pelo viés rígido e formalista, tornando-o palatável ao ponto de vista externo do sujeito econômico. Sujeito esse, de tendência ao comportamento racional e individualista e que se vê forçado a realizar trade-offs, isto é, escolhas baseadas no custo e benefício, em razão da necessidade de alocação dos recursos finitos versus os desejos ilimitados.

Daí porque o método de investigação, das lentes econômicas refletidas no objeto jurídico, serve para compreender o comportamento humano fora da realidade abstrata da norma, auxiliando os juristas no exercício do diagnóstico dos conflitos e da prognose das prováveis reações das pessoas às regras para, cientes das consequências, optarem pela melhor regra - se estiverem legislando - ou pelo melhor silogismo interpretativo - se estiverem decidindo. Por isso, a Análise Econômica do Direito é mais uma ferramenta analítica colocada à disposição dos atores jurídicos, não para oferecer a resposta correta, mas para trabalhar com conceitos operacionais como o instrumento microeconômico da Teoria dos Jogos que busca entender as instituições centrais do sistema jurídico, como no caso, as escolhidas foram o Acesso à Justiça e as técnicas de tratamento das demandas (Processo Civil e Mediação).

A Teoria dos Jogos, enquanto disciplina acadêmica é proeminente do ramo da matemática aplicada nos anos 30 do Século XX, mas foi ampliada pela Microeconomia e preconiza o estudo formal da competição e da cooperação como cenário estratégico entre as partes, pretendendo modular o comportamento na tomada das decisões. Pode ser conceituada como "teoria da decisão" a qual indica, pelo marco teórico de Robert Cooter e Thomas Ulen, o conjunto de elementos "capazes de descrever o comportamento estratégico das partes para ajudar no desenvolvimento da capacidade de raciocínio e exploração das possibilidades de interação entre os agentes, probabilidades que nem sempre correspondem à intuição. " (COOTER; ULEN, 2010, p. 56). Significa que a Teoria dos Jogos preocupa-se com a forma como os jogadores tomam suas decisões, visando assegurar o melhor resultado para si, com base naquilo que imaginam que será o movimento do outro participante, de forma que o resultado será a soma das decisões de um indivíduo e das estratégias escolhidas pelos demais.

A Teoria dos Jogos é desenvolvida pela interação entre os agentes numa estrutura denominada de jogo; cuja ideia exprime o sistema de regras de ganhos e perdas numa situação de cooperação ou 
conflito (COOTER; ULEN, 2010, p. 57). Os jogos, em sentido genérico, revelam-se quando as pessoas estão envolvidas conscientemente entre si, na medida em que a tomada da decisão de um sujeito afeta diretamente o resultado da decisão do outro. $\mathrm{O}$ modo de funcionamento do jogo compõe-se do modelo competitivo ou não cooperativo: nesse tipo não há comunicação e colaboração entre os participantes, de modo que a estratégia dominante é aquela que diminui ao máximo a possibilidade de perda e leva ao mesmo tempo a maior desvantagem ao adversário, cujo resultado final terá a somatória igual à zero, se ganha àquilo que o outro perde. Também pode apresentar-se como jogo cooperativo: nesta modalidade, ao reverso da outra, há comunicação entre os jogadores e permite-se a negociação mútua. A estratégia dominante é a opção coletiva de perder um pouco do lucro, ao invés de arriscar todos os ganhos e, por isso, consequentemente, não existe um ganhador e um perdedor, pois o resultado será diferente de zero.

Os jogos são, portanto, todas as maneiras de interações compostas por participantes que buscam satisfazer suas necessidades e, nas quais, as suas decisões interferem nas reações dos demais, havendo previsão dos resultados frente à imposição vertical de regras.

Estabelecido o ponto de partida da teoria dos jogos perfectibilizado no conceito genérico de jogo, acrescenta-se que a estrutura é formada pelos jogadores ou players, chamados também de participantes ou agentes que tomam decisões analisando o custo e benefício das suas escolhas. Os participantes são denominados jogadores (indivíduos ou grupos) porque ao interagirem possuem capacidade para tomar uma decisão e afetar a escolha dos outros agentes, havendo recíproca expectativa no comportamento do outro (COOTER; ULEN, 2010, p. 57).

Os jogadores possuem como principal objetivo alcançar o melhor resultado possível para si, considerando as preferências de todos os atores envolvidos e, dessa forma, o responsável por decisões escolhe a melhor ação segundo suas preferências. Os jogadores presumidos limitados racionalmente e com comportamento estratégico para atingir e maximizar seus objetivos são aqueles que participam da jogada com o escopo de obter determinado resultado e empreendem na interação uma conduta competitiva ou cooperativa.

Os players agem baseados em estratégias como num plano de ação, objetivando alcançar o melhor resultado, ou seja, maximizando os ganhos e diminuindo as perdas, mas sempre obedecendo às regras que determinam os princípios e as normas limitadoras das jogadas. Portanto, o liame interativo entre os jogadores se constrói sob a égide de regras, no exame das possíveis ações do seu opoente, e, ainda, nas consequências que uma decisão tem na tomada do outro, razão pela qual se torna importante delimitar as estratégias adotadas. Eis o terceiro elemento da teoria dos jogos: o comportamento estratégico dos jogadores, que ocorre antes da definição da jogada, pelo conhecimento da ação dos demais participantes, tendo em vista que saber o conjunto de ações de cada jogador é passo fundamental na análise do processo de interação estratégica. 
De acordo com Fiani (2006, p. 35) as "estratégias são os planos de ações que especificam, para cada jogador, quais atitudes devem ser consideradas nos momentos de decisão”. Ora, ao partir-se do pressuposto que os agentes desejam maximizar os ganhos e diminuir as perdas, a questão central ao eleger a estratégia é justamente tentar prever os ganhos e as perdas potenciais que existem em cada alternativa. Em termos simples, numa situação de conflito, a estratégia deve equacionar o que se mostra mais vantajoso: colaborar pela cooperação mútua ou abster-se para uma decisão de competição.

Por último, da evolução no processo de jogada, desde a escolha pelos participantes das suas estratégias até a obediência das regras, chega-se ao momento dos resultados, ganhos ou recompensa obtidos ou, como usualmente emprega a linguagem teórica, aos payoffs, "podendo ser +1 (para o ganhador), -1 (para o perdedor) e 0 (caso de empate).” (BÊRNI, 2004, p. 45). Depois de definidos os participantes, apresentadas as regras, a jogada avança com o comportamento estratégico para obtenção do resultado pelos ganhos ou pelas perdas e solução do jogo, declarando quem vence x quem perde ou traduzindo-se num valor numérico.

Neste âmbito, a cada estratégia adotada, os jogadores, por consequência, desenvolvem suas ações com vistas às retribuições e à maximização dos resultados, independentemente das condutas beneficiarem ou prejudicarem os demais. Tendo em vista que o objetivo do jogo é alcançar o seu encerramento, todas as táticas serão compostas para atingir o maior resultado, seja ele ganho, retorno ou recompensa e, ao partir do delineamento dos payoffs para cada participante, afigura-se o fim da estrutura da teoria dos jogos.

Portanto, a Teoria dos Jogos consiste no processo de interação entre dois ou mais jogadores que, mediante a combinação de estratégias, abrem espaços para a convergência do maior resultado, podendo ser aplicada ao Direito com o objetivo de demonstrar o comportamento estratégico dos litigantes frente aos sistemas de estabilização dos conflitos, em especial nas técnicas do Processo Civil e da Mediação.

\section{APLICAÇÃO DA TEORIA DOS JOGOS NO SISTEMA DE ESTABILIZAÇÃO DOS CONFLITOS}

A Teoria dos Jogos revela que toda interação pode ser definida de acordo com as suas formas de conflito e cooperação, mostrando o caminho de gestão no tratamento das demandas. A trajetória perpassa, inicialmente, pela mudança paradigmática em compreender o Direito como jogo, já que em ambos os casos aparecem comportamentos de cooperação, competência, luta e conflito, em que o resultado não depende somente de sorte, mas da performance dos jogadores em face do Estado Juiz.

Embora o jogo exerça função na vida, como atividade voluntária, antes mesmo da formação cultural, apresenta regras que orientam as condutas, mas cuja conexão está estreitamente relacionada com competição e ganho. Nesse âmbito, reside à essência lúdica do Direito, especialmente, no tocante aos 
sistemas de estabilização dos conflitos serem vistos como jogos, na medida em que se deparam com interações nas quais a "decisão ótima depende da escolha do outro agente econômico e que, por isso, as pessoas precisarão decidir qual a estratégia será adotada." (COOTER; ULEN, 2010, p. 58).

Joga-se ou compete-se, diz Johan Huizinga, "por alguma coisa; por alguma vitória" (HUIZINGA, 1872-1945, p. 58) e, do mesmo modo, litiga-se por alguma recompensa ou prêmio ao final, sendo inerente à jurisdição que cada uma das partes está dominada pelo desejo de ganhar sua causa. Para este autor, o jogo pode ser comparado ao Direito, especificamente, a sua categoria de jurisdição e processo, pois nestas formas os "jogadores estão motivados pela recompensa, afinal nenhum adversário deseja perder." (HUIZINGA, 1872-1945, p. 87-88-89).

Desse modo, se as partes são dominadas pelo desejo de ganhar a causa, todo jogo pressupõe a interação a qual emerge das operações próprias dos seres vivos e também das regras que norteiam as ações de quem joga. Assim, verifica-se que o Direito também é dirigido pela meta de regras e pelo sistema linguístico, os quais limitam as ações dos juristas, ao mesmo tempo em que criam condições para práticas competitivas.

A complexidade do jogo judicial constrói-se pelas relações entre as partes e os juristas, sobretudo, advogados e juízes, os quais se submetem ao dialeto jurídico e observam o procedimento. Assim, se o jogo pode ser conceituado como interação dentro do sistema de regras, assemelha-se ao Direito uma vez que este pode ser vislumbrado como atividade em contraditório com complexa interação entre jogadores, regulado pela Lei e na busca do melhor resultado a ser decidido pelo órgão julgador.

Desse modo, parece haver conexão entre Direito e jogo a partir do sistema normativo por meio do qual as regras procedimentais são pré-estabelecidas por códigos. Nesse sentido, admitir a interpretação do Direito enquanto sistema de estabilização dos conflitos, como o duelo que acusa desde o início uma tendência para assumir caracteres de jogos, implica sofrer influxos da Teoria dos Jogos, os quais são capazes de esclarecer como os usuários, ditos litigantes, constroem seus comportamentos de acordo com os incentivos ou desincentivos do sistema.

A metáfora da Teoria dos Jogos explica em quais situações o agir estratégico dos jogadores é induzido à competição (Processo Civil) e, ainda, justifica outro modelo em que o incentivo dá-se ao comportamento cooperativo (Mediação). Isso porque os litigantes ou jogadores por não se mostrarem como agentes neutros serão competidores ou cooperadores, de acordo com o modelo ou jogo de tratamento dos conflitos que lhes seja ofertado. Nesse aspecto, Miguel Carlos Teixeira Patrício (2005, p. 28) detalha que nas causas judiciais, assim como em qualquer circunstância, o jogo de interação é movido pela relação "custo versus benefício no momento da tomada da decisão, optando, consequentemente pela hipótese que ofereça maior vantagem, não necessariamente econômica". 
A análise do custo $\mathrm{x}$ benefício na decisão entre "jogar o jogo do processo ou jogar o jogo dos meios alternativos" pode ser potencializada por meio da articulação com a Teoria dos Jogos, a qual antecipa o comportamento estratégico da litigância. Desse modo, a aplicação da Teoria dos Jogos no Direito permite compreender dados que permanecem escondidos na ideia romantizada de tutela jurisdicional, pois aponta os jogadores como seres racionais, maximizadores das suas utilidades, e que são incentivados pela busca da decisão procedente do pedido, havendo sempre espaço para competição.

Logo, no sentido amplo, o Direito pode ser visto como jogo a partir da ideia de interação entre os litigantes, além de apresentar-se como sistema regido por regras que estruturam as jogadas. Em nível específico, o jogo é Direito porque todo jogo lembra competição e, nesse quadrante, a competição é elemento intrínseco da jurisdição e da dogmática processual, uma vez que se recompensa o ganhador ao final com a procedência da decisão judicial.

Portanto, a Teoria dos Jogos no Direito infere conclusões a partir das interações entre os agentes, isto é, auxilia a ter compreensão sobre o comportamento estratégico competitivo ou cooperativo de cada litigante nos sistemas de estabilização dos conflitos.

\subsection{O MODELO COMPETITIVO DO PROCESSO CIVIL: A NÃO COOPERAÇÃO E O “GANHA X PERDE"}

Subsidiado pela Teoria dos Jogos, o Processo Civil é composto pela interdependência das jogadas, na medida em que não se trata de jogo solitário, pois o resultado não decorre exclusivamente das jogadas individuais, mas de jogadas articuladas legalmente, sempre dialéticas, em contraditório. Desse modo, o jogo do processo depende da tomada de decisões em cadeia, na qual, no decorrer do procedimento judicial, é possível vislumbrar o cotejo da estratégia do adversário, antecipar a melhor jogada possível e os ganhos ou prejuízos.

No jogo processual, aproveitando o potencial dinâmico da Teoria dos Jogos, a interação representa-se pelo contraditório e pela comunicação dos jogadores até a tomada da decisão pelo julgador. Para entender a proposta, os lugares no jogo são preenchidos pelo a) julgador: juiz, desembargadores ou ministros e b) jogadores: autor e réu. Além disso, as estratégias são competitivas, dependendo das informações probatórias disponíveis pelos jogadores, a fim de estabelecerem os possíveis payoffs, isto é, os ganhos e as perdas.

A ideia, portanto, é que no Processo Civil a vitória dependa das estratégias montadas dentro do limite temporal do processo, de modo que o comportamento dos jogadores é capaz de influenciar no resultado. Detalhadamente, os litigantes tomam decisões visando à maximização de seus interesses a partir da análise de custos processuais x benefícios do valor esperado da demanda, sem considerar as externalidades ou prejuízos aos demais jogadores ou à coletividade. Disso resulta que, para alcançarem o 
fim do jogo, os jogadores adotam estratégias sob a ordem da competição, pois o "propósito básico do debate forense é conquistar a vitória verbal contra o oponente impressionando a plateia; o que importa é vencer o debate. "(WATSON, 2006, p. 5). O autor L.A Becker (2012, p. 149 e 163), de modo enfático, atribui ao processo à ideia de competição:

\begin{abstract}
Enquanto atividade "lúdica", focada na necessidade de vencer a qualquer custo, não só o embate entre o bem e o mal é irrelevante para o processo civil, mas também a busca da verdade [...]. Por tudo isso, talvez fosse interessante dizer que o processo é como o jogo de futebol entre os gahukugama, da Nova Guiné: um jogo tratado como um rito. Um jogo (igualdade formal, busca da vitória - desigualdade) sob a pele de rito (falácia do caráter conjuntivo: "pacificação social uma ova, o que eu quero é vencer"). O difícil é conjugar a planetária diferença de temporalidade entre os dois "jogos": no futebol, julgamento e execução imediatos à infração; já o processo é um jogo que consegue faça de ser infinitas vezes mais lento que o Banco Imobiliário. De qualquer modo, o processo é um jogo complexo.
\end{abstract}

Logo, o Processo Civil é o combate entre os litigantes, uma vez que funciona como duelo em que o fato fundamental é a destreza no manejo dos argumentos e das provas, até porque os jogadores são impulsionados pela recompensa do julgamento procedente do pedido, afinal, ninguém entra no jogo processual (ajuíza ou contesta uma ação) para perder ou cooperar.

Assim, é forçoso reconhecer que o Processo Civil se orienta pelo agir estratégico voltado para racionalidade na obtenção da vitória sobre o adversário, exatamente como num jogo. Além disso, assume natureza adversarial, na medida em que a busca pela comprovação da verdade se torna tarefa exclusiva das partes, isto é, os jogadores serão adversários ${ }^{1}$ numa competição que será decidida pelo Estado. Este caráter "híbrido ou misto" de carga inquisitiva e adversarial transparece que "atividade lúdica do processo está focada na necessidade de vencer a qualquer custo, ou seja, "a parte quer mesmo vencer, sendo-lhe de menor importância a justiça do resultado. ” (MOREIRA, 2010, p. 345).

Assim, é a própria estrutura do modelo de jurisdição, caracterizada pela oposição de interesses entre as partes, e a atribuição pelo Estado Juiz de um ganhador e um perdedor que faz do instrumento um jogo não cooperativo de resultado soma zero, como bem explica Flávio Portela Almeida (2003, p. 188):

\footnotetext{
O processo judicial contencioso é um jogo não-cooperativo. De fato, até pelo próprio fato de ser a conciliação uma das causas de extinção do processo com julgamento de mérito, se as partes não conciliaram muito provavelmente não colaborarão com a parte ex adversa no decorrer do processo judicial. Além de ser jogo não-cooperativo, o processo judicial pode ser descrito como um jogo de soma zero. De fato, a não-cooperação, conforme já exposto, é característica ínsita dos jogos de soma zero, porque a cooperação implicaria a vitória do adversário. Ademais, não há, pela própria estrutura judicial, motivação para que as partes cooperem, já que é o próprio Estado que financia o procedimento, tendo em vista o pagamento dos funcionários e juízes, necessários ao bom funcionamento da estrutura do poder judicial.
}

\footnotetext{
${ }^{1}$ Ressalta-se que no jogo processual, embora adversárias e sem estímulo à cooperação material, as partes devem obedecer à regra mínima, estando vedado o agir de má fé.
} 
Nessa perspectiva, pode-se considerar que o Processo Civil é jogo não cooperativo de resultado de soma zero, tendo em vista que a vitória do autor ou do réu implica a derrota do outro, não havendo por parte das regras processuais qualquer estímulo à estratégia cooperativa, ao contrário, há incentivo ao esgotamento das vias recursais. Mesmo tratando-se de um jogo de soma zero, o processo judicial não tem, necessariamente, o ponto de equilíbrio no qual ambos adversários conseguem assegurar a utilidade mínima. Isso porque a decisão fundamentada se dá com base nas regras normativas e, sendo assim, para cada ponto controvertido uma das duas partes necessariamente será vitoriosa e a outra derrotada, ou ambas, parcialmente derrotadas no caso de procedência parcial.

No Processo Civil vigora a estratégia da negociação competitiva ou ganha $\mathrm{x}$ perde, pois se desconsidera o relacionamento com a outra parte em longo prazo e objetiva-se maximizar todas as vantagens possíveis de modo que apenas um lado ganhe. Para Peter Stark (1999, p. 102), neste tipo de negociação ganha x perde, uma das partes, porque "valoriza apenas os próprios objetivos, se favorece em detrimento da outra, utilizando todos os meios possíveis para conseguir o que se quer. " Daí porque, nesta espécie de jogo processual, o confronto é desgastante, destrutivo, além de apresentar resultado negativo. Desse modo, se o sistema processual detém estrutura competitiva, consequentemente não abre espaço para estratégia cooperativa ou concessão mútua quanto a bens disponíveis entre as partes ${ }^{2}$, já que o fato de cada um buscar o melhor para si levará a uma situação que não é melhor para todos.

A percepção de que se faz necessário em um determinado conflito que uma parte vença a outra, “se ele ganha eu perco e vice e versa" (VEZZULLA, 1995, p. 36), e não objetivamente resolvam os pontos divergentes, faz com que os jogadores envidem esforços para ganhar do outro, impossibilitando a negociação direta entre as partes, pois o interesse de um, de ficar com tudo, induz ao outro a situação de perda total.

Assim, cresce o autoritarismo do Poder Judiciário, pois as decisões mantêm-se verticalizadas, deixando-se de perceber a dimensão do "outro" que "não sou eu nem meu grupo social, mas o "diferente" diante do qual tenho deveres e responsabilidades, e não somente direitos a opor. " (OLIVEIRA; LANGOSKI). Isso porque a condição de jogador no processo judicial acaba por distanciar os sujeitos uns dos outros, malgrado a necessidade imperativa de vitória no julgamento procedente dos pedidos. Assim, na busca por tratamento dos conflitos sob a tutela jurisdicional, cada qual pode vencer ou perder a demanda, e, por isso, nas salas dos Tribunais, reconhece-se muitas vezes nos rostos neutros das partes os verdadeiros duelantes, já que as partes apenas buscam a vitória legitimada pelo terceiro; Estado Juiz.

\footnotetext{
2 Ainda que o Magistrado julgue parcialmente procedente o pedido cujo resultado implica em ganhos e perdas mútuas, tal situação não retrata o agir estratégico cooperativo entre as partes, uma vez que a decisão de "colaboração" é imposta pelo Estado.
} 
Nesse sentido, forma-se a matriz hermenêutica do Direito por meio do consenso induzido pelo Juiz e não pelo acordo construído entre as partes.

Desse modo, o contencioso Processual Civil detecta a carga disfuncional negativa ao manter o binômio "ganhador x perdedor", razão pela qual é preciso atentar para a mudança de mentalidade com o abandono de velhas práticas, invertendo a lógica competitiva do Processo Civil a qual apenas retroalimenta a cultura da litigância e obstaculiza o adequado Acesso à Justiça.

O paradigma do Poder Judiciário, responsável pelo tratamento dos conflitos resolve a demanda de "maneira violenta", em razão da função de jurisdição focada no Processo Civil orientar-se pelo modo adversarial e formal. Por conseguinte, a estabilização dos conflitos pelo Processo Civil como modelo de justiça competitiva induz ao agir não cooperativo entre as partes, cuja prática, quando não desestimulada por políticas judiciárias, proporciona ganho individual em curto prazo, mas acarreta prejuízos coletivos a médio e longo prazo.

\subsection{A ESTRATÉGIA DA MEDIAÇÃO: A COOPERAÇÃO PARA O “GANHO X GANHO”}

Os mecanismos de resolução alternativa dos conflitos permitem que as partes, mediante técnicas de tratamento conjunto dos problemas, negociem cooperativamente e obtenham a solução do "ganho $\mathrm{x}$ ganho". De todas as práticas alternativas, uma, em especial, embasa o estudo do presente artigo, com vistas à ampliação do paradigma competitivo da lógica processual que é a Mediação ${ }^{3}$ - a "arte de compartir." (WARAT, 2004 p. 40). Assim, impõe-se a contracultura com relação ao modo adversarial, código binário e competitivo do "ganhador x perdedor" prestado pela dogmática Processualista para abertura de outro código, também binário, mas cujo formato recorda o "ganha x ganha" na estabilização dos conflitos.

Isso porque, não cabe mais apoiar-se somente no mito do Poder Judiciário fragmentado na sua força fundadora, posto que o Órgão revela-se hipertrofiado com tantas demandas, devendo-se admitir o tratamento plural da justiça, ou seja, a democratização do Acesso à Justiça. Mais do que o princípio do contraditório, que apenas denuncia a natureza disjuntiva da tutela processual pelo Poder Judiciário, é necessário reafirmar a maneira "ecológica de resolução dos conflitos sociais e jurídicos, uma forma na qual o intuito de satisfação do desejo substitui a aplicação coercitiva e terceirizada de uma sanção legal. " (WARAT, 2001, p. 5).

É tempo de resgate da "ética da alteridade que significa o respeito e o reconhecimento da integridade do outro enquanto sujeito também de direito, " (BUBER, 2004), admitindo a autonomia dos

\footnotetext{
${ }^{3}$ Convém mencionar que a Resolução 125 do CNJ, o Novo Código de Processo Civil - Lei 13.105 - 16 de março de 2015 e a Lei 13.140/2015 - Lei de Mediação formam o minissistema Brasileiro de métodos consensuais de intervenção nos conflitos, sendo suas normas complementares naquilo em que não conflitarem. Se houver conflito, as normas da Lei Mediação prevalecem por se tratar de lei posterior e específica.
} 
indivíduos na estabilização dos seus conflitos. Um novo modelo de Justiça que não se mostra distante do Direito Fraterno porque trabalha com o envolvimento e o diálogo com o outro, repensando o comprometimento coletivo no processo de auto responsabilização, desde que se libere da rivalidade destrutiva típica do modelo "irmãos x inimigos". (RESTA, 2004, p. 13).

O modelo "irmão x inimigo", construído pelo autor Eligio Resta, dá-se a partir da experiência social dos cidadãos no Estado Nação que apenas compartilham a língua comum, sem construírem elos entre si. Por esta razão o autor entende que seja necessária à adoção da Lei de amizade, a qual aproxima as pessoas e auxilia no reconhecimento da identidade, torna submissa a sociedade ao código fraterno (entre irmãos) e cria relações solidárias sob o ponto de vista do comprometimento coletivo (RESTA, 2004, p. 28 e 50).

Adaptando-se o ponto de vista teórico da fraternidade de Eligio Resta à tutela jurisdicional pelo processo judicial vê-se que este tratamento de conflito recorda a categorização das partes como inimigas, mormente porque os litigantes jogam o jogo do processo interessados egoisticamente em alcançar a maximização das vantagens para si. Não há, nesta perspectiva, aproximação dos interesses dos litigantes, tampouco, pensamento coletivo.

No entanto, é possível centrar políticas de inclusão no reconhecimento do outro, de aproximação das partes com o processo de auto responsabilização; comprometimento com todos, desde que se reserve a visão paternalista do Juiz apenas para os casos dos bens indisponíveis, e, se insira, outro modelo de justiça; justiça do tipo cooperativo que envolve modelo de composição e gestão dos conflitos menos autoritariamente decisórios. Especialmente, uma justiça da proximidade pautada na autonomia das partes e na relação de cooperação pactuada e convencionada. A mudança de paradigma da cultura do conflito para a cultura da paz requer não apenas a não existência do conflito, mas a participação e o diálogo entre os sujeitos com cooperação mútua. Assim, a forma de saltar de um paradigma para outra se faz por meio da Mediação. (LANGOSKI, 2013, p. 184)

O jogo em que é possível a criação da justiça cooperativa, isto é, baseada no diálogo, autonomia, horizontalidade e alteridade, chama-se "jogo da Mediação", a qual transparece ser proposta "transformadora do conflito", pois não busca a decisão pelo terceiro, mas sim a resolução pelas próprias partes as quais recebem auxílio do mediador. Isso porque na Mediação pressupõe-se restabelecer a relação horizontal entre os homens, destacando-se como instrumento capaz de tratar os conflitos nessa perspectiva, já que sua dinâmica aborda os sujeitos, autonomia e o diálogo. (LANGOSKI, 2013, p. 186).

Pautada na autonomia da vontade, a abordagem mediadora convida as pessoas a trabalharem com a negociação que "identifique aquelas coisas que você pode conceder ao seu oponente e que representa um alto benefício para ele, mas que não custem muito à você” (URY, 1991, p. 113). Como processo de reconstrução simbólica, a Mediação representa a técnica informal em que o terceiro neutro, 
sem poder para impor sua decisão auxilia as partes a alcançarem o acordo mutuamente aceitável, cuja formulação incorpora o caráter consensual e a voluntariedade na disputa.

Da aceitabilidade, conjugada com o voluntarismo, a Mediação devolve ao particular a responsabilidade pela gestão do conflito, fugindo das decisões prolatadas pelos Juízes, por meio do código binário "ganhador x perdedor", permitindo aos litigantes o comprometimento com o outro mediante a elaboração de acordos participativos. Infere-se que no procedimento da Mediação, as relações deixam de centralizar-se nos termos "ou-ou", que significa ou ganha ou perde, para firmar bases fraternas na expressão "e-e", representada pelo tópico ganha e ganha ou perde e perde, como forma de reconectar (união fraterna) os sujeitos separados pelo conflito.

Embora possa soar anormal representar a Mediação como jogo, uma vez que este por sua natureza recorda a ideia de competição, conforme já mencionado, todo jogo pressupõe interação e desenvolvimento de estratégias que podem ser competitivas ou cooperativas, conforme o interesse dos envolvidos. Nesse âmbito, a Mediação não foge à regra, visto que admite ação recíproca entre os participantes e é coordenada pelo mediador na busca do melhor resultado para ambos. Logo, se há interação, há jogo, porém na Mediação, diferente do Processo Civil, a matriz tática vincula-se à estratégia cooperativa.

Modulando os comportamentos dos personagens tem-se que na Mediação os jogadores são os interessados e fazem parte do mesmo "time", pois não se encaram como adversários e, voluntariamente, ali se encontram para alcançarem os propósitos coletivos no tratamento do conflito. Há, ainda, o mediador, terceiro imparcial entre as partes, que busca reatar a comunicação entre os participantes para que estes encontrem os payoffs dos ganhos e diminuindo as perdas.

Por esta premissa, a própria natureza do mecanismo da Mediação incentiva os "jogadores" a realizarem o comportamento fraterno baseado no agir cooperativo, porquanto devolve às partes o protagonismo sobre a solução das suas contendas, já que não será unilateral do primeiro, tampouco do segundo, mas uma saída original realizada por ambos e que não pertença a nenhum dos dois propriamente.

Assim, na Mediação, o comportamento estratégico das partes volta-se para barganha do "ganho x ganho", ou seja, para negociação do tipo cooperativa. A tática da justiça fraterna pela colaboração é possível desenvolver-se na Mediação, uma vez que todo o mecanismo está envolto da ideia da aproximação das partes pelo mediador que deve funcionalizar entre elas a estratégia cooperativa, chegando-se ao acordo em que ambas partes se beneficiem e sintam que suas necessidades foram atendidas.

O interessante na Mediação, diferente dos demais métodos, principalmente do jogo competitivo da tutela jurisdicional pelo Processo Civil, não é vencer o outro enquanto adversário numa alusão à 
guerra, mas multiplicar os ganhos para os dois participantes, considerando que nem sempre ambos os lados ganharão na mesma proporção, porém terão maiores benefícios em longo prazo.

Para que a estratégia cooperativa se torne dominante, a solução conjunta dos problemas não deve centrar-se nas posições dos jogadores, mas sim nos seus interesses, identificando as preocupações, necessidades, temores, desejos que subjazem e, motivam as posições encontradas. A barganha posicional deixa de produzir diálogo na medida em que quanto mais se procura esclarecer o outro lado da impossibilidade de modificar a posição inicial, mais difícil se torna fazê-lo.

No interior da Mediação, diferentemente da dogmática processual, não há posições firmadas entre autor x réu de modo que é possível barganhar interesses e não posições, obtendo ganhos mútuos. Ora, se a estratégia presente na mediação retrata a cooperação, o mecanismo enquadra-se no jogo cooperativo. Comentando sobre o tema, Flávio Portela Lopes de Almeida (2003, p. 190) discorre:

\begin{abstract}
A mediação, a rigor, é um jogo cooperativo. Não poderia ser de outra forma, já que, se uma das partes não quiser cooperar, a outra pode simplesmente abandonar o processo, sem sofrer ônus algum. Além disso, a própria função do mediador, tanto na mediação facilitadora quanto na avaliadora, que é a de fazer com que as partes entendam os sentimentos e interesses da adversária, promove uma maior possibilidade de cooperação no processo. Ressalte-se que a cooperação está diretamente relacionada às informações disponíveis às duas partes: muito possivelmente uma das partes não cooperará fornecendo à outra parte informações prejudiciais a si. Por outro lado, a presença do mediador força, ao menos, a possibilidade de um equilíbrio de Nash, já que, pela própria presença de um terceiro neutro ao processo, as partes tenderão a encontrar um acordo mutuamente satisfatório do qual ambas não deverão se arrepender no futuro. A presença do mediador garante isso porque as partes sentir-se-ão constrangidas em oferecer propostas irreais ou em permanecer a posições fixas de negociação, o que possibilita que a discussão focalize os interesses reais das partes.
\end{abstract}

Especificamente, sob as justificativas da Teoria dos Jogos, compara-se a Mediação ao jogo cooperativo, porque este valoriza a comunicação entre os jogadores, já que por meio da conversa permitese interação coletiva e o alcance do maior ganho possível para todos. No mesmo caminho, ocorre na Mediação: a dinâmica preconiza o diálogo entre os jogadores e alerta que a competição entre os agentes leva ao resultado pior individualmente do que se houvesse cooperação, uma vez que a estratégia dominante competitiva é prejudicial para todos.

Na Mediação, os jogadores, até porque se deixam voluntariamente submeter-se a esse tipo de mecanismo, bem como por causa da presença do mediador, são incentivados a colaborarem entre si para concluírem acordos satisfatórios, criando estratégias cooperativas e, firmando a justiça nos moldes fraternos. E, desta forma, a inclusão da estratégia cooperativa vislumbrada na Mediação contribui para a exequibilidade do direito ao Acesso à Justiça na medida em que abandona a ideia de acesso limitado aos Tribunais, numa tempestiva e efetiva estabilização dos conflitos.

Portanto, o Acesso à Justiça, com a aplicação da Teoria dos Jogos, pode ser melhorado reduzindo a forma de justiça competitiva presente no Processo Civil para outro modelo de justiça, 
desenvolvida pela técnica da Mediação, porque resta comprovado que nesse método admite-se a estratégia cooperativa.

\section{CONSIDERAÇÕES FINAIS}

A cultura da litigância reflete a distorção e a carga negativa e anormal do conflito, de forma que a ideia geral inserida no (in) consciente imaginário do coletivo é que todo e qualquer conflito necessita ser judicializado e resolvido sob a forma de uma solução adjudicada, dotada de força estatal imperativa e coercitiva, fundada na lógica do "vencedor x perdedor. O pseudo sentimento de proteção da cidadania trouxe consigo o mito do Tribunal de "Hércules", isto é, aquele Poder Judiciário que ditará quem será o vencedor e o perdedor e determinará o encerramento dos conflitos, resistindo à práxis pacificadora do "ganhador x ganhador".

Entretanto, não se pode mais aceitar uma justiça incapaz de enxergar que o uso desproporcional do direito de ação como único instrumento de salvaguardar todas as demandas, acarreta na ineficiência do Poder Judiciário. Assim, a fim de defender solução minimamente consensuada entre as partes e o redimensionamento do tema Acesso à Justiça de modo a não confundi-lo socialmente com o direito de buscar proteção apenas nos Tribunais, aplicou-se a Teoria dos Jogos nos sistema de estabilização dos conflitos, especificamente no Processo Civil e na Mediação.

Partindo do comportamento dos jogadores e das recompensas, a Teoria Econômica dos Jogos descreve a estrutura tensionada entre o autor e réu no Processo civil como um sistema de justiça competitivo e com resultado de soma zero (ganha x perde), incentivando os participantes a elaborarem estratégias não colaborativas. Ao contrário, na Mediação, cuja comparação recorda ao jogo cooperativo com payoff diferente zero (ganha x ganha), por não haver imposição Estatal e as partes não se encararem como inimigas são facilitadas pelo diálogo, com vistas à maximização dos ganhos coletivos.

A busca pela satisfação e benefícios mútuos denota a diferença do jogo competitivo do Processo Civil, cujo formato em sua estrutura não estimula o comportamento cooperativo entre os jogadores, da estratégia presente na Mediação que se orienta pela comunicação bidirecional entre as partes com vistas a conciliar interesses e não posições. Conciliando interesses e não posições, a Mediação cumpre a função de jogo cooperativo na medida em que a decisão não será de um, nem de outro, mas de ambos e, cuja soma do resultado, será diferente de zero (ganho x ganho), alcançando a eficiência do acordo positivo entre as partes.

Portanto, se o objetivo do presente artigo era verificar os instrumentos do acesso à justiça a partir da teoria dos jogos conclui-se que com a redução da justiça competitiva do Processo Civil para outra forma de justiça, desenvolvida pela Mediação entre as partes, chega-se a facilitação do acesso à justiça na medida em que a técnica da mediação admite a estratégia cooperativa entre as partes. 


\section{REFERÊNCIAS}

ALMEIDA, Flávio Portela Lopes de. A teoria dos jogos: uma fundamentação teórica dos métodos de resolução de disputas. In: AZEVEDO, André Gomma de (Org.). Estudos em arbitragem, mediação e negociação. Brasília: Ed. Grupos de Pesquisa, 2003. v. 2, p. 160-180.

BECKER, L.A. Qual é o jogo do processo. 2. ed. Porto Alegre: Sergio Antonio Fabris, 2012.

BÊRNI, D.Á. Teoria dos Jogos: jogos de estratégia, estratégia decisória, teoria da decisão. Rio de Janeiro: Reichmann \& Affonso, 2004.

BUBER, Martin. Eu e tu. Tradução Newton Aquiles Von Zuben. 8 ed. São Paulo: Centauro, 2004.

CAPPELlETTI, Mauro; GARTH, Bryant. Acesso à justiça. Tradução de Ellen Gracie Nortfleet. Porto Alegre: Sérgio Antônio Fabris; 1988.

COOTER, Robert; ULEN, Thomas. Direito e Economia. Tradução de Luis Marcos Sander; Francisco Araújo da Costa. Porto Alegre: Bookman, 2010.

LANGOSKI, Deisemara Turatti. Direito e Fraternidade. Coord. Josiane Rose Petry Veronese; Olga Maria Bochi Aguiar de Oliveira. In: Mediação familiar e fraternidade: desafios e perspectivas para a cultura da paz. Rio de Janeiro: Lumen Juris, 2013, p. 183-209.

MERCURO, Nicholas. Derecho y Economia. Madrid: Instituto de Estudios Fiscales, 1991.

FIANI, Ronaldo. Teoria dos Jogos: para cursos de administração e economia. 2.ed. Rio de Janeiro: Elsevier, 2006.

HUIZINGA, Johan. Homo ludens: o jogo como elemento da cultura. 2. ed. Tradução João Paulo Monteiro. São Paulo: Perspectiva, 1872-1945.

MOREIRA, José Carlos Barbosa. O neoprivatismo no processo civil. In: DIDIER JR., Fredie (org.). Leituras complementares de processo civil. 8 ed. Salvador: Juspodivm, 2010.

OLIVEIRA, Olga Maria Boschi Aguiar de; LANGOSKI, Deisemara Turatti. A sustentabilidade como expressão do princípio da fraternidade. Disponível em: <http://www.publicadireito.com.br/artigos/?cod=e3d2b39d8bc215f6>. Acesso em: 22 abr. 2016.

PATRÍCIO, Miguel Carlos Teixeira. Análise Económica da Litigância. Coimbra: Almedina, 2005.

RESTA, Eligio. O direito fraterno. Trad. de Sandra Regina Martini Vial. Santa Cruz do Sul: Edunisc, 2004.

RODRIGUES, Horácio Wanderlei. Acesso à Justiça no direito processual brasileiro. São Paulo: Acadêmica, 1994.

STARK, Peter B. Aprenda a negociar: o manual de táticas ganha/ganha. São Paulo: Littera Mundi, 1999, p. 102. 
URY, William. Supere el No: Cómo negociar com personas que adoptan posiciones obstinadas. Barcelona: Grupo Editorial Norma, 1991.

VEZZULLA, Juan Carlos. Teoria e prática da mediação. Curitiba: Instituto da mediação, 1995.

WARAT, Luis Alberto. O ofício do mediador. Florianópolis: Habitus, 2001.

WATANABE, Kazuo. Modalidade de Mediação. In: José Delgado et al. Mediação: um projeto inovador. Brasília: Centro de Estudos Judiciários, 2003.

WATSON, Douglas. Lógica informal. São Paulo: Martins Fontes, 2006. 